\section{A VISIT TO PAPWORTH VILLAGE SETTLEMENT.}

PAPWORTH HaLl, some five miles from Huntingdon, was once a large country house surrounded by many acres of beautiful and well wooded gardens. Twelve years ago the Hall was opened as a sanatorium, and around it has grown up an industrial village populated by patients.

Many a patient who is apparently cured and remains well as long as he is in a sanatorium relapses soon after he leaves the institution and is quite unable to lead an ordinary life or compete in the markets of the world. What to do with such patients is one of the great problems of tuberculosis, and of the many schemes for "after care" none has proved so satisfactory as the village colony. To train a consumptive to an occupation, however light, and then cast him into the world to make his way against heavy odds is quite futile, for these men are substandard men, and the idea of the village settlement is to have a colony where the workers, damaged as they are, can make their way.

Short periods of sanatorium life alternating with periods at home, often in crowded cities and unsuitable homes, do not meet the problem, for under this system the patient is not only a useless member of the community but is actually dangerous to others. Moreover, the knowledge that he is unfit for useful work and the absence of hope make life intolerable. Papworth is made up of substandard men and women and each one has hope. In the hospital or sanatorium the patients strive to get well enough to go to the workshops, and there they can work and support themselves by their own industry. The fact that the hospital beds at Papworth are continuously full and that the discharges against advice are uil, bears testimony to the contentment of the patients. From the hospital the patient passes on to the sanatorium section and there he begins to learn some vocation. This training is part of the treatment and the patient later goes into the village settlement where he is first partially and then wholly self-supporting, so that employment is used first as a therapeutic agent and later as a means of livelihood. Dr. Varrier Jones, the Medical Director, in his report writes : "If we fail to restore him (the patient) to a position of complete independence, we must see to it that we get him as near as possible to it. It has been calculated that since 1918 the cost per ex-patient in the industries is between $£ 3$ and $f 4$ per annum and this cost falls as the industries grow. That is to say the subsidy required is practically negligible. That a subsidy is required I have always insisted, but it is so small as to be a practical proposition. It is, however, only kept within these bounds by the most careful medical supervision, not only of the patients who receive training in the various workshops (no patient is allowed to work if his evening temperature is $99^{\circ} \mathrm{F}$. or over), but of the ex-patients who work there as a means of earning their living. All these definite cases of tuberculosis require infinite care to prevent over-exertion which may mean a relapse, and in order that their exercise should have a definite therapeutic value. This should always be borne in mind. The health of the worker must be the first consideration, the balance sheet will then take care of itself. Reverse this order and disaster quickly follows."

When the patient is fit to enter the settlement, that is to say when he ceases to be a patient, he is still under medical supervision, but it is most unusual for a relapse to occur necessitating a return to sanatorium or hospital.

Life in the village, though quiet, is very happy. The number of cottages available for the married ex-patients is steadily increasing, but more are required, for there is no limitation to the size of the colony. Doubt has been cast on the wisdom of bringing up children in such surroundings, but after twelve years' experience no child 
whilst a member of Papworth community has contracted tuberculosis in any known clinical form and those who have left the settlement to seek employment elsewhere are all free from disease.

The workshops themselves are full of interest and the workmanship is of high standard. Goods are bought by large firms and individual customers, not from compassion but because of their quality. The industries include furniture and cabinet making and a variety of other occupations. These industries are growing rapidly, and the sales, which in I919 were $£ 3,935$, rose to $£^{1,400}$ in 1927 , so it is obvious that very genuine work is being done.

\section{ROUND THE WARDS.}

A GIRL of 13 was doing her school work, playing games and apparently in perfect health until May 6, when on returning from school she complained of headache and was found to have a temperature of roo. On May 8 she had a sore throat with some painful glands in the neck and her temperature rose to 105 . By May ${ }_{5} 5$, the throat was no longer sore and the glands of the neck had subsided but the child was acutely ill with a continuous temperature of $\mathrm{r}^{0} 5^{-103}$. The tongue was dry and there were some hæmorrhages from the lips' and gums, the spleen was palpable and a few rhonchi were heard over both lungs. The possibilities of typhoid or miliary tuberculosis were considered, but the Widal reaction was negative and the acuteness and severity of her condition seemed against tuberculosis. A bloodcount was made on May 19, and showed R.B.C. I,750,000 ; hæmoglobin, 39 per cent. ; W.B.C., 4,200; myeloyctes, 66 per cent.

She died on May 23, after an illness of seventeen days. Post-mortem showed extreme hyperplasia of the red marrow.
The blood-count suggests that the case was one of acute myelocytic leukæmia, which is very rare. The small white-cell count was probably a terminal condition.

\section{POST-GRADUATE NEWS.}

Owing to vacation it is not possible to arrange for many Special Courses to be held during the month of August. The Fellowship of Medicine has organized courses in three different subjects, and a few remarks concerning each will be, perhaps, of help to our readers. From August 8 to September I the Staffat the All Saints' Hospital will provide a course of instruction in genito-urinary diseases, consisting of clinical and cystoscopic demonstrations. -Fee $£ 2$ 12s. 6d. Those engaged in welfare centres will have an opportunity of taking a special course under Dr. Eric Pritchard and his staff at the Infants Hospital from August I3 to August 25. Instruction is by demonstration or by lecture, and interesting visits are arranged to be made to other centres, such as to the Blind Babies' Home at Chorley Wood, the Nursery Training School at Hampstead, \&c. Fee $t 33$ s.

For those desiring a "brush-up" in medicine, in surgery and the specialities, there will be an all-day course at the Queen Mary's Hospital, Stratford, E. 15, from August 27 to September 8. The work provided will consist of demonstrations in general medicine, general surgery, orthopædics, laryngology, genito-urinary surgery, \&c. This hospital possesses a fine pathological department, and there are opportunities provided for attending antenatal clinics and maternity wards (in the latter forty beds are available). Arrangements are made for obtaining luncheon in the neighbourhood, and tea is provided at the hospital. This course should make a strong appeal 